
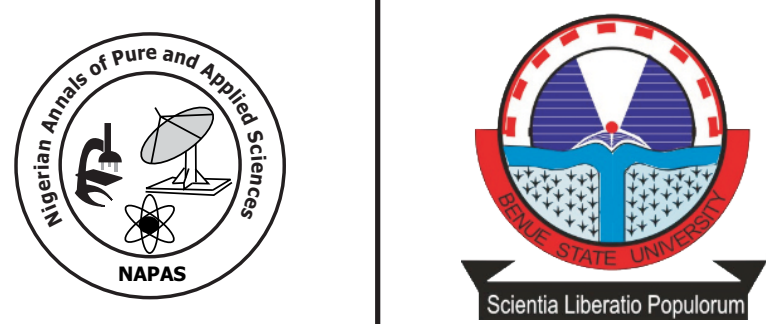

\title{
Antiplasmodial activities of the combined leaves extracts of Morinda lucida, Phyllantus Amarus, Vernonia Amygdalina and Newbouldia laevis
}

\author{
Idowu, E.T. ${ }^{1}$, Abdulwahab, M.M. ${ }^{2}$, Fagbohun, I.K. ${ }^{1}$, Ajaegbu, H.C.N. ${ }^{2}$, \\ Aina $^{3} 0.0,0$ tubanjo, 0. . $^{1}$ \\ ${ }^{1}$ Department of Zoology, University of Lagos, Akoka, Yaba, Lagos, Nigeria \\ ${ }^{2}$ Nigeria Natural Medicine Development Agency, \\ Federal Ministry of Science and Technology, Lagos \\ ${ }^{3}$ Biochemistry Division, Nigerian Institute of Medical Research, Yaba, Lagos \\ *Corresponding author: etidowu@gmail.com
}

\begin{abstract}
The development of resistance to some synthetic antimalarial drugs and the spread of counterfeit antimalarial drugs, has become a global problem. It has affected effective malaria treatment, making the development of new drugs exigent. Certain medicinal plants contain potent ingredients such as alkalloids, flavonoids, glycoside and volatile oils, which suppress the spread of plasmodial infections, and are widely used within the tropics for treatment of malaria. This study was designed to investigate the antiplasmodial activities of the combined aqueous extract of Morinda lucida, Phyllantus amarus, Vernonia amygdalina and Newbouldia laevis at variable doses in Swiss albino mice infected with Plasmodium berghei (NK65). Fifty mice were randomized into ten groups which were divided equally for suppressive and curative test. Four days suppressive and 5 days curative test were used to assess the antiplasmodial activities of the extract in mice infected with chloroquine sensitive $P$. berghei at concentration of $200 \mathrm{mg} / \mathrm{kg}, 400 \mathrm{mg} / \mathrm{kg}$ and $800 \mathrm{mg} / \mathrm{kg}$ body weight. Furthermore the levels of aspartate aminotransferase (AST), alanine aminotransferase (ALT) and alkaline phosphate (ALP), urea and creatinin were determined by standard procedural methods to evaluate impact of extracts on hepatic and kidney function. The results of the 4 days suppressive test revealed that the test extract achieved percentage suppression of $9.8 \%, 58.3 \%$ and $60.2 \%$ for $200 \mathrm{mg} / \mathrm{kg}, 400 \mathrm{mg} / \mathrm{kg}$ and $800 \mathrm{mg} / \mathrm{kg}$ concentration respectively. The curative test achieved the highest parasitaemia reduction with $800 \mathrm{mg} / \mathrm{kg}$ $\left(29.5 \pm 29.1 \times 10^{3}\right)$ which was comparable to the standard antimalarial drug, chloroquine. There were significant elevation in the values of AST and ALT at $400 \mathrm{mg} / \mathrm{kg}$ and $800 \mathrm{mg} / \mathrm{kg}$ respectively suggesting hepatic dysfunction. However, ALP and urea showed no significant different $(\mathrm{P}>0.05)$, but creatinin showed significant difference $(\mathrm{P}<0.05)$ only at $200 \mathrm{mg} / \mathrm{kg}$. This study shows that the combined leaves extract demonstrated antimalarial activities.
\end{abstract}

Key words: Antiplasmodial, oxidative enzymes, plant extracts 


\section{Introduction}

Approximately 3.2 billion people are at risk of malaria, with an estimated 214 million cases and 432,000 deaths annually (WHO, 2016). Malaria related deaths are caused by Plasmodium falciparum infection and most of the cases of malaria are in children under five years and pregnant women (Dondorp et al, 2009). Presently malaria chemotherapy remains the mainstay of malaria control in sub-Saharan Africa. The advent of development of resistance to chloroquine necessitates the introduction of artemisinin based combination therapy to combat resistance in malaria endemic countries, however resistance to artemisinin based combination therapy has already been reported in South East, Asia and in some parts of Africa.

Africa flora is greatly rich with a lot of medicinal plants which indigenous people are familiar with and have used over time (Dike et al., 2012). Ethnobotanical surveys have shown that these plants and herbs are effective especially in the treatment of malaria (WHO, 2002) and the use of medicinal herbs has been a common method of treating malaria among people living in malaria endemic areas (Ahmad, 2014). Different parts of plant such as leaf, bark, stem, roots and fruit are used to treat malaria. The medicinal plants used for the treatment of malaria are usually taken orally in the form of infusions (hot teas), decoctions (boiled teas), tinctures (alcohol and water extracts), paste, powder and macerations (cold-soaking) (Idowu et al., 2010; Kunle et al., 2013).

Morinda lucida is an important medicinal plant in Nigeria and the evaluation of antiplasmodial activities of Morinda lucida extract revealed significant chemosuppression (Unekwuojo et al., 2011). Antiplasmodial activity of aqueous and ethanolic extracts of Phyllantus. amarui whole plants and leaves have been demonstrated against Plasmodium yoelii (Ajala et al., 2011; Dapper et al., 2007). Vernonia amygdalina leaves are used as green leafy vegetable and consumed either as a vegetable (leaves are macerated in soups) or aqueous extracts used as tonics for the treatment of various illnesses (Igile et al., 1995). Both aqueous and alcoholic extracts of the stem, bark, roots and leaves are reported to be extensively used as antimalarial (Kupcham, 1969; Njam, 2012). Newbouldia laevis is widely used in African folk medicine and antiplasmodial potential of $N$. laevis has been documented (Andrew et al., 2016)

Phytochemical analysis of these leave extracts have been attributed to wide range of metabolites including, glycosides, saponins, flavonoids, anthraquinones, reducing sugar, steroids, terpenoids and alkaloids. polyphenols, terpenes, carotenoids, coumarins, volatile oils anthraquinones and steroids terpenes, steroids, coumarins, phenolic acids, lignans, (Kupcham, 1969; Odetola and Akojenu, 2000; Izevbigie, 2003; Akinmoladun et al., 2010; Amonkan et al., 2013; Adeyemi et al., 2014; Saganuwan, 2014 and Andrew et al., 2016).

In preparation of herbal recipes for malaria therapy, a single plant (monotherapy) or combination with other plants (combination therapy) could be used (Idowu et al., 2015). The combination of these different plants has been claimed to cure and ameliorate several ailments and dysfunctions associated with malaria in the body and it has been speculated that the active ingredients of each plant in the preparation complemented one another in the fight against malaria parasite (Ibrahim et al., 2012). Furthermore, most studies where combined leaves extracts have been demonstrated for antimalarial activities have failed to demonstrate the impact of these extracts on kidney and liver. The study therefore explores antimalarial suppressive and curative activities of the combined aqueous extracts of Morinda lucida, Phyllantus amarus, Vernonia amygdalina and Newbouldia laevis and assess influence of these extracts on the liver and kidney function in mice.

\section{Materials and methods \\ Plant collection and identification}

The four medicinal plants used in this study were selected based on their traditional use to treat malaria locally. The leaves of the following plants, Morinda lucida (Brime stone) "Oruwo", Phyllantus amarus (Stone breaker) "Eyin olobe", Vernonia amygdalina (Bitter leaf) "Ewuro" and Newbouldia laevis (fertility tree) "Akoko" were collected from Alaba Suru market in Lagos. The identification and authentication were done by the Ethno-Survey Unit, Research and Training Department, Nigeria Natural Medicine Development Agency and Federal Ministry of Science and Technology, Lagos.

\section{Plant preparation}

The plant materials (leaves), were spread thinly on a flat, clean tray (to prevent spoilage by moisture condensation) and allowed to dry at room temperature for two weeks. The dried plant materials were pulverized separately into powder using an electric blender and then stored in an airtight container prior to extraction.

\section{Plant extraction}

The pulverized plants were mixed together 
in a ratio of $2: 1: 1: 1$. Approximately 4.2 grams of Morinda lucida and 2.1 grams of Phyllantus amarus, Newboldia laevis and Vernonia amygdalina and mixed together to make a total of 10.5 grams. The combined plant was extracted with $750 \mathrm{ml}$ of water boiled at $100^{\circ} \mathrm{C}$ for 24 hours. The preparation was filtered and the filtrate was kept in a well-sealed container and stored in the refrigerator till it was used for the experiment.

\section{Drugs preparation}

Tablets of chloroquine phosphate, CQ (Emzor Pharmaceutical company, Nigeria), $(0.05 \mathrm{~g})$ was dissolved in $10 \mathrm{ml}$ of Phosphate Buffered Saline (PBS) to final doses of $5 \mathrm{mg} / \mathrm{kg}$ body weight which served as positive control.

\section{Animals}

Fifty pure strains of adult Swiss albino mice weighing between 15-30grams were obtained from the animal house, Nigeria Institute of Medical Research (NIMR), Yaba Lagos. The animals were kept in clean and well maintained cages in the Biochemistry Laboratory of NIMR. The animals were observed under 10 hours light/dark cycles in clean and well maintained cages in the Biochemistry laboratory and were fed with mice pellet diet (Ladokun Farms, Ibadan, Nigeria) and water ad libitum for one week so as for them to acclimatize to room temperature of $29^{\circ} \mathrm{C}$. This method was carried out prior to randomization into various experimental groups of five (5) animals per group based on body weight of the mice. The groups were designated as group A (200mg), B (400mg), C (800mg), CQ and Negative control.

\section{Preparation of parasites and innoculum}

A chloroquine-sensitive Plasmodium berghei (NK65 strain) obtained from the Biochemistry Division, NIMR, was used for this study. Experimental mice were infected with blood samples from donor mouse which was obtained by ocular puncture, using a sterile capillary tube. The infected blood was diluted with phosphate buffered saline which enabled innoculum of $0.1 \mathrm{ml}$ for each mouse containing $10^{6}$ parasitized red blood cells intraperitoneally.

\section{Antiplasmodial studies of plant extracts Suppressive treatment}

The Peters' 4 days suppressive test was adopted in this study (Peter, 1965). Twenty five mice of both sexes weighing 14-19grams were innoculated intraperitoneally with 106 erythrocytes in $0.1 \mathrm{ml}$ phosphate buffered saline and randomized into five groups, A, B, C, D and E with each group having five (5) animals in a cage. Treatment of animals started after 2 hours on Day 0 . Group A, B and C served as the experimental groups, while group $\mathrm{D}$ and $\mathrm{E}$ served as the control groups. Group D served as the positive control group which was administered with $30 \mathrm{mg} / \mathrm{kg}$ chloroquine phosphate and group $\mathrm{E}$ served as negative control group which was not treated at all. Group A, B and C were treated with three selected doses per kg body weight (200, 400 and $800 \mathrm{mg}$ ) of the combined extract for four (4) days and group D was treated with chloroquine phosphate for 3 days. The animals were administered with the extract 2 hours after the inoculation of the parasite on day 0 (D0) and everyday till day 3 (D3) using an oral cannular. On day 4, thin and thick films were made from the tail blood of each mouse under aseptic conditions. The thin films were prepared by spreading the blood on a clean glass slide at angle 45 degrees, and subsequently fixed with methanol. The thick and thin films were stained with 3\% Giemsa stain for 45 minutes and examined with microscope under the oil immersion objective to determine the parasite density microscopically (Olympus CX, Japan). This is necessary as to monitor the level of parasitaemia. The suppression of parasitaemia in relation to the control was assessed using the recommended formular.

Average $(\mathrm{Av}) \%$ suppression $=$

$\mathrm{Av} \%$ parasitaemia in control $-\mathrm{Av} \%$ parasitaemia in test $\times 100$ $\mathrm{Av} \%$ parasitaemia in control.

\section{Curative treatment}

Ryles and Peters procedure was adopted in this study (Ryles and Peters, 1970). On day 0, twenty five (25) Swiss albino mice were randomized into A, B, C, D and $\mathrm{E}$ with each group having five animals. Inoculation was intraperitoneal and all mice were inoculated with106 parasitized red blood cells in $0.1 \mathrm{ml}$ of phosphate buffered saline. Treatment started 72 hours after inoculation. Group A, B and C served as the experimental group and were administered with three selected doses per kg body weight (200, 400 and $800 \mathrm{mg}$ ) of the combined extract orally for five (5) days using an oral canular. Group D served as the positive control administered with a curative dose of $30 \mathrm{mg} / \mathrm{kg}$ of Chloroquine for three (3) days through oral canular. The preparation of thick blood films commenced 72 hours after inoculation and lasted for ten days. The level of parasitaemia was calculated based on parasite density. Number of parasite counted against 200 white blood cells (WBC), multiply by 8000 
Parasite density $=$

No of parasite X 8000 $200 \mathrm{WBC}$

\section{Determination of biochemical parameters of the liver and kidney}

On the 10th day post inoculation, $5 \mathrm{ml}$ of fresh blood was collected from three mice from each group by ocular puncture. The blood was used for the biochemical analysis of the liver and kidney, for quantitative determination of alanine aminotransferase (ALT), aspartate aminotransferase (AST) and alkaline phosphatase (ALP), urea and creatinine (Cr).

ALT and AST levels were measured with commercially available standard blood ALT and AST kits by Randox, Reitman and Frankel (1957). The plasma urea level was measured with commercially available standard blood urea kit by (Randox, United Kingdom). The plasma creatinine level was measured with commercially available standard blood creatinine kit (Randox United Kingdom) (Bartels et al., 1972)

\section{Statistical analysis}

Mean and standard deviation of the results of suppressive and curative treatment were calculated using Excel package, which is expressed in mean \pm Standard deviation. Results of biochemical analysis of kidney and liver were subjected to One-way Analysis Of Variance (ANOVA), using SPSS. The results were also expressed in mean \pm Standard deviation (SD) and the level of significance was estimated at $\mathrm{P}<0.05$. Differences among groups were determined by Duncan multiple range test.

\section{Results}

The result of this work shows that the combined extract did not cause mortality within 24hours at all doses. In the suppressive test, two mortalities were recorded in 800 and $400 \mathrm{mg} / \mathrm{kg}$. Two death were recorded in $400 \mathrm{mg} / \mathrm{kg}$, one in $800 \mathrm{mg} / \mathrm{kg}$, one in positive control (Chloroquine) and three in negative control in the curative test.

\section{Parasitaemia suppression}

There was significant reduction of parasitaemia $(\mathrm{P}<0.05)$ in the treatment group compared to the negative control. Chloroquine (CQ) $(30 \mathrm{mg} / \mathrm{kg})$ gave an absolute $(100 \%)$ reduction (Table1). The parasitaemia reduction was dose dependent with $800 \mathrm{mg} / \mathrm{kg}$ having the highest reduction $(5.3 \pm 3.66)$. The percentage suppression of the groups treated with 200,400 and $800 \mathrm{mg} / \mathrm{kg}$ were $9.8,58.3$ and $59.8 \%$ respectively, indicating that suppression increases with increasing dosage of the combined extract. CQ gave $100 \%$ suppression (Table 1).

\section{Clearance of parasitaemia}

The result of this study signifies that the combined extract showed a potent antiplasmodial activity against Plasmodium berghei rodent malaria in vivo at doses of 200,400 and $800 \mathrm{mg} / \mathrm{kg}$. Total clearance of the parasites was not achieved by the combined extract but the clearance was dose dependent (Table 2).

Chloroquine attained absolute parasitaemia clearance from day one (D1) till day nine (D9). Among the doses, $800 \mathrm{mg} / \mathrm{kg}$ attained the highest level of parasite clearance on D7 (147.9 \pm 125.35$)$, followed by $400 \mathrm{mg} / \mathrm{kg}$ on D1 (15.81.2 \pm 8.72$)$ and $200 \mathrm{mg} / \mathrm{kg}$ on D2 (23.93 \pm 23.12$)$ (Table 2$)$.

Two hundred milligram had a higher parasite clearance compared to the negative control on D1 $(27.89 \pm 30.05)$ but the parasitaemia count shot higher on D7 (147.9 \pm 125.35$)$. Four hundred milligram maintained a higher level of parasite clearance throughout the study compared to the negative control, but the parasite count shot a bit higher on D8 $(55.53 \pm 19.44)$ compared to the negative control, $800 \mathrm{mg}$ had a higher parasite clearance with the highest clearance (29.51 \pm 29.14$)$ on D7 (Table 2).

\section{Biochemical assessment of the liver and the kidney}

Table 3 showed no significant difference in the level of ALP and Urea at all doses $(\mathrm{P}<0.05)$. AST had significant decrease $(\mathrm{P}>0.05)$ at $200 \mathrm{mg} / \mathrm{kg}(35.7 \pm 6.9)$, ALT showed significant increase at $800 \mathrm{mg} / \mathrm{kg}(81.2 \pm 6.2)$ compared to the positive control and creatinine had significant increase at doses $400 \mathrm{mg} / \mathrm{kg}(1.4 \pm 0.2)$ and $800 \mathrm{mg} / \mathrm{kg}(0.9 \pm 0.5)$. 
Table 1: Suppression rate of parasitaemia by combined extract of Morinda lucida, Phyllantus amarus, Vernonia amygdalina and Newbouldia laevis in Plasmodium berghei infected mice

\begin{tabular}{lllll}
\hline Treatment & Groups & Dose $(\mathrm{mg} / \mathrm{kg})$ & $\begin{array}{l}\text { Mean Parasitaemia count } \pm \text { S.D } \\
\text { (in thousand) }\end{array}$ & $\begin{array}{l}\text { Suppression of } \\
\text { parasitaemia }\end{array}$ \\
\hline Control -ve & $\mathrm{A}$ & & $13.2 \pm 3.05$ & \\
Control +ve & $\mathrm{B}$ & & - & 100 \\
Combined & $\mathrm{C}$ & 200 & $11.9 \pm 5.42$ & 9.8 \\
Extract & $\mathrm{D}$ & 400 & $5.5 \pm 2.65$ & 58.3 \\
& $\mathrm{E}$ & 800 & $5.25 \pm 3.66$ & 60.2 \\
\hline
\end{tabular}

Table 2: Curative assay of the combined extract of Morinda lucida, Phyllantus amarus, Vernonia amygdalina and Newbouldia laevis in Plasmodium berghei infected mice

\begin{tabular}{|c|c|c|c|c|c|}
\hline \multicolumn{6}{|c|}{ Dosage in $\mathrm{mg} / \mathrm{kg}$ body weight } \\
\hline \multirow[t]{2}{*}{ No of Days } & $200 \mathrm{mg}$ & $400 \mathrm{mg}$ & $800 \mathrm{mg}$ & CQ & Negative \\
\hline & & & & & Control \\
\hline & \multicolumn{5}{|c|}{ Parasitaemia counts for the treatment days (in thousands) } \\
\hline DO & $88.19 \pm 10.62$ & $17.83 \pm 18.9$ & $10.53 \pm 708.66$ & $23.39 \pm 22.61$ & $27.42 \pm 33.65$ \\
\hline D1 & $27.9 \pm 30.05$ & $15.81 \pm 87.25$ & $43.21 \pm 29.00$ & 0 & $59.55 \pm 53.25$ \\
\hline D2 & $23.93 \pm 23.12$ & $19.37 \pm 11.37$ & $51.07 \pm 24.21$ & 0 & $31.34 \pm 32.00$ \\
\hline D3 & $75.93 \pm 60.88$ & $44.45 \pm 32.95$ & $107.94 \pm 77.49$ & 0 & $76.89 \pm 65.07$ \\
\hline D4 & $97.98 \pm 82.39$ & $73.87 \pm 25.57$ & $137.56 \pm 154.29$ & 0 & $97.93 \pm 52.85$ \\
\hline D5 & $70.56 \pm 48.83$ & $51.10 \pm 32.13$ & $18.50 \pm 58.77$ & 0 & $76.66 \pm 27.13$ \\
\hline D6 & $48.34 \pm 24.50$ & $55.20 \pm 35.30$ & $23.84 \pm 12.94$ & 0 & $52.38 \pm 19.66$ \\
\hline D7 & $147.90 \pm 125.35$ & $58.74 \pm 31.30$ & $29.51 \pm 29.14$ & 0 & $75.67 \pm 45.34$ \\
\hline D8 & $60.24 \pm 11.52$ & $55.53 \pm 19.44$ & $19.31 \pm 16.25$ & 0 & $40.61 \pm 26.00$ \\
\hline D9 & $144.20 \pm 78.51$ & $99.70 \pm 46.45$ & $105.78 \pm 149.05$ & 0 & $123.33 \pm 41.99$ \\
\hline
\end{tabular}

Table 3: Biochemical assessment of Plasmodium berghei infected mice treated with combined extract of Morinda lucida, Phyllantus amarus, Vernonia amygdalina and Newbouldia laevis and control groups

\begin{tabular}{llllll} 
Parameters & $200 \mathrm{mg} / \mathrm{kg}$ & $400 \mathrm{mg} / \mathrm{kg}$ & $800 \mathrm{mg} / \mathrm{kg}$ & + ve Control & -ve Control \\
AST $(\mu / \mathrm{L})$ & $35.7 \pm 6.9^{*}$ & $96.3 \pm 6.7$ & $1.2 \pm 3.7$ & $79.3 \pm 21.9$ & $1.9 \pm 32.9^{*}$ \\
ALT $(\mu / \mathrm{L})$ & $26.1 \pm 11.9$ & $26.7 \pm 5.9$ & $81.2 \pm 6.2^{*}$ & $28.8 \pm 5.3$ & $94.8 \pm 7.9^{*}$ \\
ALP $(\mu / \mathrm{L})$ & $99.3 \pm 9.8$ & $1.2 \pm 7.8$ & $1.8 \pm 56.6$ & $65.3 \pm 152$ & $1.7 \pm 35.5$ \\
Urea $(\mathrm{mg} / \mathrm{dl})$ & $77.5 \pm 4.6$ & $98.2 \pm 2.6$ & $68.5 \pm 0.9$ & $25.2 \pm 5.6$ & $96.1 \pm 16.7^{*}$ \\
Cr $(\mathrm{mg} / \mathrm{dl})$ & $0.8 \pm 0.7$ & $1.4 \pm 0.2^{*}$ & $0.9 \pm 0.5^{*}$ & $0.6 \pm 0.9^{*}$ & $0.8 \pm 0.3$ \\
\hline
\end{tabular}

$\mathrm{AST}=$ Aspartate transaminase, $\mathrm{ALT}=$ Alanine transaminase, $\mathrm{ALP}=$ Alanine Phosphatase

$\mathrm{Cr}=$ Creatinine $*=$ Significant difference

\section{Discussion}

The emergence of Plasmodium falciparum multi-drug resistant malaria and drug resistance to artemisinin-derivatives and to other drug combination therapies makes the development of new potent antimalarial drugs an alternative therapy. Traditional medicinal plants have proved to be rich sources of new drugs coupled with the fact that antimalarial drugs in use presently were either obtained directly from plants or developed using chemical structures of plant-derived compound as templates. The feasibility of discovering new potent antimalarials from traditional medicinal plants is very promising.

This study demonstrated the in vivo antiplasmodial activities of aqueous leaves extracts of a combination of Morinda lucida, Phyllantus amarus, Vernonia amygdalina and Newbouldia laevis. The significant chemosuppression demonstrated in the extract treated group is in agreement with the traditional use of combined extract herbal medication against malaria in many part of Nigeria (Igoli et al., 2005; Adebayo and Krettli, 2011). The extract was effective and dose dependent. The observed efficacy of the standard antimalarial drug, chloroquine $(100 \%)$ which was higher than the extract treated groups may be due to nonselectivity of the extract or slow absorption and poor bioavailability of crude extract (Adzu and Haruna, 2007).

The curative test revealed that the extract 
has a considerable high antiplasmodial effect. The extracts produce a dose dependent parasitaemia levels in the extract treated groups. The parasite reduction at $800 \mathrm{mg} / \mathrm{kg}$ treated group was similar to that of chloroquine which established that combined extracts of Morinda lucida, Phyllantus amarus, Vernonia amygdalina and Newbouldia laevis has therapeutic efficacy against malaria parasites. This finding is consistent with previous studies that have confirmed the antiplasmodial potency of the four individual plants (Abosi and Raseroka, 2003; Ajala et al., 2011; Unekwuojo et al., 2011; Njam, 2012; Andrew et al., 2016). The antimalarial activity could be attributed to the presence of some phytochemicals like alkaloids, saponins, flavonoids, taninis, terpenes and cardiac glycosides present in the plants. These constituents have been found in other natural products which exhibite antimalarial activity (Ayoola et al., 2008). The compounds could be acting singly or in synergy with one another to exert the antimalarial activity observed in this study. Saponins, flavonoids, alkaloids and tannins have been suggested to act as primary antioxidants or free radicals scavengers that can counteract the oxidative damage induced by malaria parasite (Alli et al., 2011; David 2004 and Okonkon et al., 2008).

Aspartate aminotransferase (AST) and Alanin aminotransferase (ALT) level increased in $400 \mathrm{mg} / \mathrm{kg}$ and $800 \mathrm{mg} / \mathrm{kg}$ respectively. The increase significantly differ from the negative control but are not significantly different from the values of the positive control. This suggests that the impact of the extract was masked by the hepatoprotective effect of Morinda lucida (Oduola, et al., 2010). The level of alkaline phosphate (ALP) showed no significant difference in all the experimental groups, suggesting the leakage in AST and ALT at 400 and $800 \mathrm{mg} / \mathrm{kg}$ respectively was from the liver and not the bile duct (Idowu et al., 2015). Increased serum level of AST and ALT are reported to be associated with liver damage (Mukherje, 2003).

There was no significant difference in the values of urea between the extract treated groups and chloroquine treated group, but were significantly different from the negative control. However, creatinine showed significant difference only at the lowest dose $(200 \mathrm{mg} / \mathrm{kg})$ which was not significantly different from the negative control. This implies that the extract impacted the kidney at $200 \mathrm{mg} / \mathrm{kg}$, but the impact was suppressed at higher doses $(400$ and $800 \mathrm{mg} / \mathrm{kg}$ ). This could be attributed to the hepatoprotective effect of Morinda lucida (Oduola, et al., 2010). Urea and creatinine are markers of kidney function, elevation of these markers indicates an impairment of the kidney.

Recent successes recorded in malaria control can be jeopardized by malaria drug resistance and the WHO aim of eliminating malaria 2030, local plants that have showed antiplasmodial activities should be fully assessed for their effectiveness and the possibilities of using them as new antimalarial drugs.

\section{References}

Abosi, A. O. and Raseroka, B. H. (2003). In vivo antimalarial activity of Vernonia amygdalina. British Journal of Biomedical Sciences. 60(2): 89-91.

Adebayo, J. O. and Krettli, A. U., (2011). Potentials of anti-malarias from Nigerian plants: A review. Journal of Ethnopharmacology. 133:289-302.

Adeyemi, T.O.A., Ogboru, R.O., Idowu, O.D., Owoeye, E.A. and Isese, M.O. (2014). Phytochemical screening and health potentials of Morinda lucida Benth. International Journal of Innovation and Scientific Research. 11(2): 515-519.

Ajala, T.O., Igwilo, C. I., Oreagba, I. A. and Odeku, O.A. (2011). The antiplasmodial effect of the extracts and formulated capsules of $P$. amarus on Plasmodium yoelii infection in mice. Asian Pacific Journal of Tropical Medicine. 4: 283-287.

Akinmoladun, A. C., Obuotor, E. M. and Farombi, E. O. (2010). Evaluation of antioxidant and free radical scavenging capacities of some Nigeria indigenous medicinal plants. Journal of Medicinal Food. 13(2): 444-451.

Alli, L. A., Adesokan, A. A., Salawu, O. A., Akanji, M. A., and Tijani, A. Y. (2011). Antiplasmodial activitry of aqueous root extract of Acacia nilotica. African Journal of Biochemistry Research. 5: 214:219.

Amonkan, A. K., Kamagaté, M., Yao, A. N.R., Konan, A. B., Kouamé, M. N., Koffi, C., Kati-Coulibaly, S. and Die-Kakou, H. (2013). Comparative Effects of Two Fractions of Phyllanthus amarus (Euphorbiaceae) on the Blood Pressure in Rabbit. Greener Journal of Medical Sciences. 3 (4): 129-134.

An Overview of Evidence and Pharmacology. In: Toxicity and Drug Testing, Acree (Ed.). InTech publisher.

Andrew, E. T., Adeyemi, M. M. and Salihu, L. ( 2016). In vitro Antiplasmodial Activity and Phytochemical Screening of Newbouldia laevis Used in Treating Malaria-associated Symptoms. British Journal of 
Pharmaceutical Research. 9(3): 1-8.

Ayoola, G. A., Coker, H. A., Adesegun, S. A., Adepoju-bello,A.A., Obaweya, k., Ezennia, E. C. and Atangbayila, T. O. (2008). Phytochemical screening of antipxidant activities of some selected medicinal plants used for malaria therapy in Southwestern Nigeria. Tropical Journal of Pramaceutical Research. 7: 1019-1024.

Bartels, H., Böhmer, M., \& Heierli, C. (1972). Serum creatinine determination without protein precipitation. Clinica chimica acta; international journal of clinical chemistry, 37, 193-197.

Dapper, D. V., Aziagba, B. N. and Ebong, O.O. (2007). Antiplasmodial effects of the aqueous extract of Phyllanthus amarus Schum. and Thonn. against Plasmodium berghei in Swiss albino mice. Nigerian Journal of Physiological Sciences 22: 19-25.

David, A. F., Philip, J. R., Simon, L. C., Reto, B., and Solomon, N. (2004). Antimalarial drug discovery: efficacy models for compound screening. Nature Reviews. 3: 509-520.

Dike, P. I., Obembe, O. O. and Adebiyi, E. F. (2012). Ethnobotanical survey for potential anti-malarial plants in south-western Nigeria. Journal of Ethnopharmacology. 144: 618-626.

Dondorp, A. M., Nosten, F., Yi, P. Das, D., Phyo, A. P., Tarning, J., Lwin, K. M., Ariey, F., Hanpithakpong, W., Lee, S., Singhasivanon, P., Ringwald, P., Silamut, K., Imwong, M., Chotivavich, K., Lim, P., Herdman, T., An, S. S., Yeung, S., Day, N. P., Lindegardh, N., Socheat, D. and White, N. J. (2009). Artemisinin resistance in Plasmodium falciparum malaria. New England Journal of Medicine. 361:455-67.

Idowu, E. T. Ajaegbu, H. C. N, Omotayo, A. I., Aina, O. O. and Otubanjo O. A. (2015) In vivo anti-plasmodial activities and toxic impacts of lime extract of a combination of Picralima nitida, Alstonia boonei and Gongronema latifolium in mice infected with Chloroquine-sensitive Plasmodium berghei. African Health Sciences. 15(4):1262-1270.

Idowu, O. A., Soniran, O. T., Ajana, O. and Aworinde, D. O. (2010). Ethnobotanical survey of antimalarial plants used in Ogun State, Southwest Nigeria. African Journal of Pharmacy and Pharmacology. 4(2): 055060.

Igile, G.O., Oleszek, W., Burda, S. and Jurzysta, M. (1995). Nutritional assessment of
Vernonia amygdalina leaves in growing mice. Journal of. Agriculture and Food Chemistry. 43:2162-2166.

Igoli, J. O., Ogali, O. G., Tor-Anjiin, T. A. and Logli, N. P. (2005). Traditional medicine practice amongst the Igede people of Nigeria Part II. African Journal of Traditional, Complementary and Alternative medicine. 2:134-152.

Izevbigie, E. B. (2003). Discovery of watersoluble anticancer Agents (Edotides) from a vegetable found in Benin City, Nigeria. Experimental Biology and Medicine. 228: 293-298.

Kunle, O. F., Adache, A. A. and Omoregie, H. E. (2013). Medicinal Plants Used for the Treatment of Malaria in Rukuba, Bassa Local Government Area of Plateau State, Nigeria. International Journal of Basic and Applied Sciences. 2(4): 134-138.

Kupcham, S. M., Hernichway, R. J, Karim, A. and Wermer, D. (1969). Tumor inhibitors. XLVII. Vernodalin and vernomygdin, two new cytotoxic sesquiterpene lactones from Vernonia amygdalina Del. Journal of Organic Chemistry. 34 (12):3908-11.

Mukherjee, P. K. (2003). Plant products with hypercholesterolemic potentials. In: Taylor, Steve L. (ed.), Advance in Food and Nutrition Research 47. Elsevier Science, USA: 277-338.

Njam, A. A. (2012). Herbal Medicine in the Treatment of Malaria: Vernonia amygdalina:

Odetola, A. A. and Akojenu, S. M. (2000). Antidiarrhoeal and gastrointestinal potentials of the aqueous extract of Phyllanthus amarus (Euphorbiaceae). African Journal of Medical Science. 29: 119-122.

Oduola, T., Bello, I., Adeosun, G., Ademosun, A., , Raheem, G. and Avwioro, G. (2010). Hepatotoxicity and nephrotoxicity evaluation in Wistar albino rats exposed to Morinda lucida leaf extract. North American Journal of Medical Sciences. 2(5): 230-233.

Okokon, J. E., Ettebong, E., \& Antia, B. S. (2008). In vivo antimalarial activity of ethanolic leaf extract of Stachytarpheta cayennensis. Indian journal of pharmacology, 40(3), 111.

Peters, W. (1965). Drug resistance in Plasmodium berghei Vincke and Lips, 1948. I. Chloroquine resistance. Experimental Parasitology. 17(1):80-9.

Reitman, S., \& Frankel, S. (1957). A colorimetric method for the determination of serum 
glutamic oxalacetic and glutamic pyruvic transaminases. American journal of clinical pathology, 28(1), 56-63.

Ryley, J. F. and Peters, W. (1970). The antimalarial activity of some quinone esters. Annals of Tropical Medicine and Parasitology. 864: 209-222.

Saganuwan, S. A. Aondoaver, A. D. and Roman, I. T. (2014). Reassessment of Acute and Chronic Toxicity Effects of Aqueous Leaf Extract of Morinda lucida in Rattus norvegicus. Journal of Hematology Research. 1:36-46.

Unekwuojo, E. G., James, O. and Olubunmi, A. R. (2011). Suppressive, Curative and
Prophylactic Potentials of Morinda lucida against Erythrocytic Stage of Mice Infective Chloroquine Sensitive Plasmodium berghei NK-65. British Journal of Applied Science \& Technology. 1(3):131-140.

World Health Organization. (2016). World malaria report 2015. World Health Organization.

WHO (World Health Organization) Centre for Health Development (2002). Traditional Medicine: Planning for cost-effective traditional health services in the new century-a discussion paper. http:/www.who.or.jp/tm/research/ 